\title{
Transforming A Business Statistics Course With Just-in-Time Teaching
}

\author{
Joann Bangs, Ph.D., St. Catherine University, USA
}

\begin{abstract}
This paper describes changing the way a business statistics course is taught through the use of just-in-time teaching methods. Implementing this method allowed for more time in the class to be spent focused on problem solving, resulting in students being able to handle more difficult problems. Students' perceptions of the just-in-time assignments were overall positive.
\end{abstract}

Keywords: Just-in-Time Teaching; Active Learning

\section{INTRODUCTION}

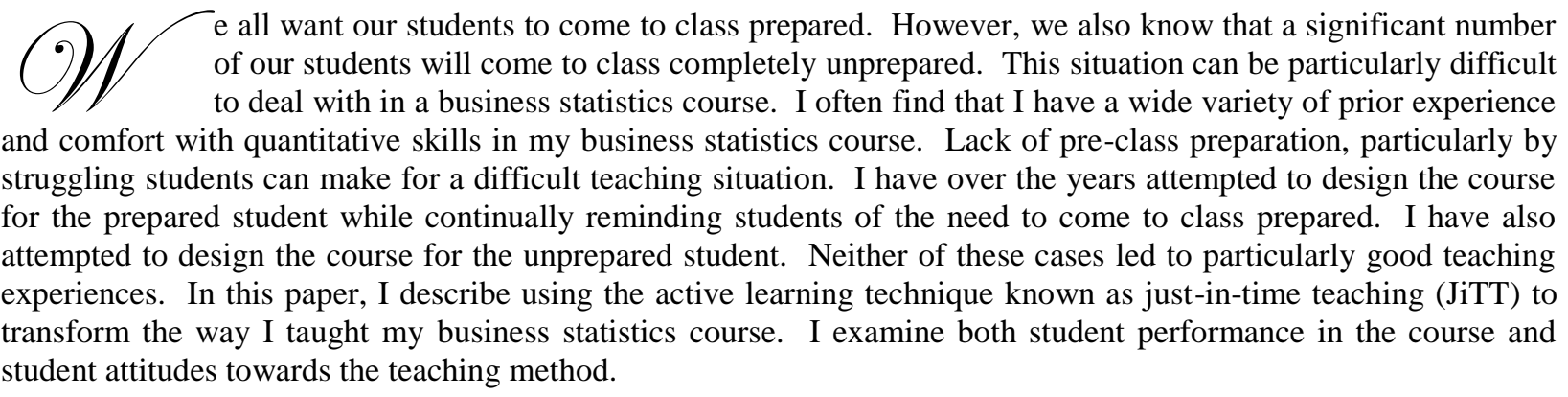

\section{SUPPORT FOR USING JiTT}

The basic process of JiTT involves assigning questions for students to complete and submit (often through a course management system) several hours or perhaps the day before the class meets. Then the instructor uses the responses from the students to shape in class activities to address learning gaps displayed in the pre-class assignments. It is this second step by the instructor that distinguishes JiTT from merely giving students a quiz on the readings. A number of studies have been done to show the effectiveness of JiTT as a teaching strategy. A nice review of these findings can be found in Simkins and Maier (2004). First and foremost amongst the benefits of JiTT is that the students come to class prepared. A well designed JiTT question helps the student to focus on particular content rather than passively reading the textbook. Other benefits of JiTT come from the process of using specific student responses (anonymously) to generate discussion in the class. Seeing their own responses used in class creates some ownership in the learning process. It helps both the students and the instructor understand where misconceptions are coming from.

Simkins and Maier (2004) also report on the effect of JiTT on learning. In their study students were randomly assigned to two different groups. The groups were assigned either JiTT exercises or alternative exercises at different points during the course. After controlling for factors such as GPA and SAT scores, they were only able to show a weak (not statistically significant) positive effect from JiTT. However, as the authors note, their process of having both groups complete JiTT exercises during different parts of the course may have affected their results. It is possible that those students that were introduced to JiTT early in the term may have changed their study habits as a result. When measuring the effect on student learning early in the course (when only one group had completed JiTT exercises to date) there was a positive JiTT effect at the $10 \%$ level of significance. Authors in other fields have also tested the effectiveness of JiTT. For example, Slunt and Giancarlo (2004) compared the use of Concept Test 
and JiTT for Chemistry students. They found that both of these active learning techniques improved student performance. However, they also found that JiTT did more to improve student participation than the Concept Test. For other examples, see Marrs and Novak (2004) for an assessment of JiTT in Biology or Grove (2002) for Geoscience.

\section{PROCESS OF USING JiTT}

I introduced JiTT into my business statistics course in the summer session of 2011. Although the course is designed for business and economics majors, there are a number of other majors that may use the course to fulfill their statistics requirement. As a consequence, there is generally a wide variety of backgrounds in and comfort with quantitative areas. Previously the course had been taught with a mixture of lecture and in-class problem solving. While the in-class problem solving seemed to be the most valuable activity in the course, I found that I was not able to devote enough time to this activity as too much time was devoted to lecture. I decided to try implementing JiTT to see if improved student preparation could lead to allowing more time for in class problem solving.

The process of using $\mathrm{JiTT}^{1}$ begins with designing good questions. One important aspect of the questions was that they needed to be complex. I found that the questions that worked best were the ones that no one was able to get completely correct. That way all of the students could be pushed in class to think beyond what they had done before the class.

The second step in the process for the instructor is to review the student responses to the pre-class questions and to then design a portion of the class meeting time around the answers given by the students. My class met once a week at night and students had to turn in the pre-class assignments the morning of the class. As I reviewed the student responses, I would categorize them by the particular approach taken by the students. Often a clear progression would emerge from these categories. I was generally able to see a path to take to describe how to approach solving a complex problem by looking at where students got stuck in the process on their pre-class assignments. I then chose a sample response to show to the class (anonymously) from each of the categories. Over the course of the term I tried to make sure I was selecting responses from as many different students as was possible.

Finally the process ends with the classroom activity. As much as possible I asked students to try to identify where there were gaps or wrong turns in the sample answers. We did this work either in small groups or as whole class discussions. This discussion would provide a spring board for a mini lecture on the concepts we were discussing that evening.

I did choose to assign grades to the pre-class assignments. I was concerned that students would not take the pre-class assignments seriously if they did not affect their grade. However, I did not wish to overly penalize the students for failing to completely solve the pre-class assignments, as I was trying to design questions that would be too difficult for the students to completely solve before class. I chose to make the pre-class assignments in total account for about $9 \%$ of their course grade. I also gave students the following rubric that I used to grade the preclass assignments.

\begin{tabular}{|c|c|l|}
\hline Grade & Points & \multicolumn{1}{c|}{ Scoring Criteria } \\
\hline A & $9-10$ & $\begin{array}{l}\text { Student answers all questions correctly and completely. Student incorporates information from the text } \\
\text { into the answer. }\end{array}$ \\
\hline B & $8-8.5$ & $\begin{array}{l}\text { Student uses statistical concepts to answer the questions. Student does not use all appropriate statistical } \\
\text { concepts. Answers may be partially correct but still not complete. }\end{array}$ \\
\hline C & $7-7.5$ & $\begin{array}{l}\text { Student uses statistical concepts to answer the questions. Student does not use appropriate statistical } \\
\text { concepts. Answers are incorrect. }\end{array}$ \\
\hline D & $6-6.5$ & $\begin{array}{l}\text { Student tries to answer the questions, but does not show evidence of using information from the text. } \\
\text { Answers are incorrect. }\end{array}$ \\
\hline F & $0-5.5$ & Student is not able to answer the questions. \\
\hline
\end{tabular}

\footnotetext{
${ }^{1}$ Starting Point: Teaching and Learning Economics (see references for URL) is a very good resource for help in getting starting
} with using JiTT. 


\section{RESULTS}

As an instructor I was very pleased with the implementation of JiTT into my business statistics course. I found that my students came into the room with a much better base of knowledge than I had seen in all previous times I had taught the course. I also found that the students came to each class with a more equal footing. Although there were certainly still differences in ability and comfort level, the struggling students were much better equipped to learn each night. I found I was able to significantly increase the amount of time I spent in class doing problem solving. As a matter of fact, the problem solving became the focus of the class each night, rather than the piece I did my best to fit in. I also found it a very refreshing experience to completely rethink my approach to the material before each class. Although I still carried the notes I had used for years to class with me each night, I found I almost never used these notes. Instead I was engaged in a much more interactive process with the students on how to apply statistical concepts. In the past I had spent much more time simply trying to explain what the statistical concepts were. Unfortunately, I cannot document any improvement in student grades. The distribution of course grades in this class looked very similar to distributions from past years. However, I did incorporate more complex questions into post-class homework assignments and exams than I had in the past. So, it seems to me as if the students completed the class with a better understanding of statistics despite the lack of change in the grade distribution.

In the last class meeting, I asked the students to complete a survey on the instructional methods used in the course. A copy of the survey questions in included in Appendix A. In the first question, I asked students to rate the usefulness of various components of the course on a 5 point scale with 1 being not at all useful and 5 being very useful. The modal response was 5 for discussing pre-class assignments in class, completing post-class homework assignments, discussing graded post-class homework assignments in class, lecture and in-class problem solving. The modal response was 3 for completing pre-class assignments, reading the textbook and solving odd number problems from the textbook. I found it interesting that students seemed to find discussing the pre-class assignments in class more useful than actually completing the pre-class assignments. (See Appendix B for a distribution of responses for these two items.) Looking at individual responses, in most cases students gave a higher usefulness rating for discussing the pre-class assignment than they did for completing the pre-class assignments. It seems that students were quite engaged in the process of discussing the pre-class questions in class, but did not make the connection to the need to have completed the problems before class in order to have such a discussion. It is also noteworthy that reading the textbook had a lower usefulness rating from the students. Again there seemed to be a disconnect for the students. The richness of the discussion of the pre-class questions came about because the students had spent time reading the textbook and attempting to complete the pre-class questions prior to class. I have had students tell me informally that they felt like they were wasting time struggling to understand the material in the textbook to complete the pre-class assignment, because it all seemed so easy once they heard me explain it in class. I continually work to explain to students that things seem easy in class because they have spent the time struggling with the material on their own first, but it seems I have not yet fixed this problem.

In the survey, I also asked students to tell me what they thought worked best about the pre-class assignments, what recommendations they had to improve the use of pre-class assignments, and whether or not they would recommend continuing to use the pre-class assignments. The reaction to the pre-class assignments was mixed, but 53\% of the students would recommend continuing to use pre-class assignments in this course. Most frequently the positive comments from students were in the area of preparedness. Students did seem to recognize that working on the pre-class assignments forced them to be prepared for class, though as noted above that did not necessarily translate to perceived usefulness of completing the pre-class assignments. The following student comments illustrate this theme:

The assignment helped me to anticipate what I would learn in class.

I really like the Fact that you gave us pre-class problems. It made the next class more interesting \& I could follow along and ask Questions where the book made me confused.

Forced me to read the chapters and helped me to understand the material being presented.

I had a heads up as to what to expect for the week. 
Although pre-class's are naturally more confusing than post-class, it seemed to be a useful way to start to understand the new material, and going over them in class solidified or clarified what we understood on our own.

It is good prep for class and motivation to stay ahead.

It is a great way to stay on top for the class. And it makes you read your text book. Without it I don't think I would have even opened it. Wonderful Idea! :)

However, there were also a number of negative comments about the pre-class questions. These responses tended to fall into themes of frustration, concern about the effect on their grade, or feeling that working from the textbook did not match their learning style. The following student comments illustrate these themes:

I didn't like these at all. It mostly made me stressed out that I had to learn something on my own and I am kind of a perfectionist so I would spend hours trying to figure some out.

I found it very hard to self teach myself how to solve the problems since reading and comprehension is a difficult learning style for me with math.

They really stressed me out ... I spent far too much time trying to figure these out.

The way I learn is through seeing others do and then modeling their work. This is why the post-homework assignment works best for me.

I also asked students to tell me how much time they spent on the pre-class assignments. Most students indicated they spent around 2 hours each week on these assignments. This time was about half the amount of time students indicated they spent on the post-class assignments (traditional homework assignments). Despite comments to the contrary, the pre-class assignments did not seem to take up too much of the students' time.

Finally I asked students to tell me about the number of points assigned to the pre-class questions. Students could indicate 'Not enough points,' 'About the right amount of points,' or 'Too many points.' The modal response (69\%) was 'About the right amount of points.' The remaining students indicated 'Too many points.' Despite the high percentage of students indicating they thought the amount of points assigned was fine, I believe lowering the number of points in the future could be beneficial. I think it might reduce some of the stress for students surrounding completing the pre-class assignments. However, it will be interesting to see if the amount of time students spent on the pre-class assignments is negatively affected by reducing the number of points assigned to them.

\section{CONCLUSION}

Despite the concerns expressed by some of my students, I consider the implementation of JiTT into my business statistics course a success. For me, the introduction of JiTT completely transformed the way I thought about the course. After teaching numerous sections of this course over the past several years, I felt completely renewed and refreshed in my teaching simply by being forced to react to the responses I received from students. However, there do remain improvements to be made the next time around. To reduce the anxiety surrounding completing the pre-class assignments, I will reduce the number of points for these. I will likely also alter the grading rubric to place greater emphasis on application of material from the reading, rather than correct application of the material from the reading. Making this change should help me to engage the students in a discussion about learning from mistakes and building our knowledge through a process. One final change I will make is to give each of the students individualized feedback on their pre-class assignments. I had made the assumption that the in-class discussion of the pre-class assignments would provide the students with enough feedback. However, comments on the student survey lead me to believe this process was not sufficient. 


\section{AUTHOR INFORMATION}

Joann Bangs has a B.S. in Economics from the University of Wisconsin-Madison, and both an M.A. and a Ph.D. in Economics from the University of Minnesota. She is currently an associate professor and chair of the Department of Economics at the St. Catherine University. Her current research interests are active learning techniques. She developed a module on context-rich problems for Starting Point: Teaching and Learning Economics. E-mail: jmbangs@stkate.edu

\section{REFERENCES}

1. Grove, Karen. (2002). Using online homework assignments to implement the learning cycle in large courses for general education, Journal of Geoscience Education, 50 (5) pp. 566-574.

2. Marrs, Kathleen A., and Novak, Gregor M. (2004). Just-in-Time Teaching in Biology: Creating an Active Learner Classroom Using the Internet, Cell Biology Education, 3 (1), pp. 49-61.

3. Simkins, Scott and Maier, Mark. (2004). Using Just-in-Time Teaching Techniques in the Principles of Economics Course, Social Science Computer Review, 22 (4), pp. 444-456.

4. Slunt, K. M., and Giancarlo, L. C. (2004). In the Classroom - Student-Centered Learning: A Comparison of Two Different Methods of Instruction. Journal of Chemical Education, 81, 7, pp. 985-988.

5. $\quad$ Starting Point: Teaching and Learning Economics. (n.d.). Just in Time Teaching (JiTT) Retrieved from http://serc.carleton.edu/econ/justintime/index.html 


\section{APPENDIX A: STUDENT SURVEY QUESTIONS}

Your participation in this survey is voluntary. If you do not wish to participate, please leave this sheet blank. If there are any questions you prefer not to answer, you may leave those blank.

1) How useful were each of the following components of the course in helping you to learn the material? Please rate the usefulness of each of these components of the course on a scale of 1 to 5 , with 1 being not at all useful and 5 being very useful.

Completing pre-class assignments

Discussing pre-class assignments in class

Completing post-class homework assignments

Discussing graded post-class homework assignments in class

Lecture

In-class problem solving

Reading the textbook

Solving odd number problems from the textbook

2) On average, how much time did you spend each week completing the pre-class assignments?

3) On average, how much time did you spend each week completing the post-class homework assignments?

4) How do you feel about the number of points possible on the pre-class assignments? Please circle your response.

$\begin{array}{lll}\text { Not enough points } \quad \text { About the right amount of points } & \text { Too many points }\end{array}$

5) How do you feel about the number of points possible on the post-class homework assignments? Please circle your response.

Not enough points About the right amount of points Too many points

6) What worked best about our process of using the pre-class assignments to discuss new material?

7) What recommendations do you have to improve the process of using the pre-class assignments to discuss new material?

8) Overall, would you recommend continuing to use pre-class assignments in this course? Why or why not? 
APPENDIX B: SELECTED SURVEY RESULTS
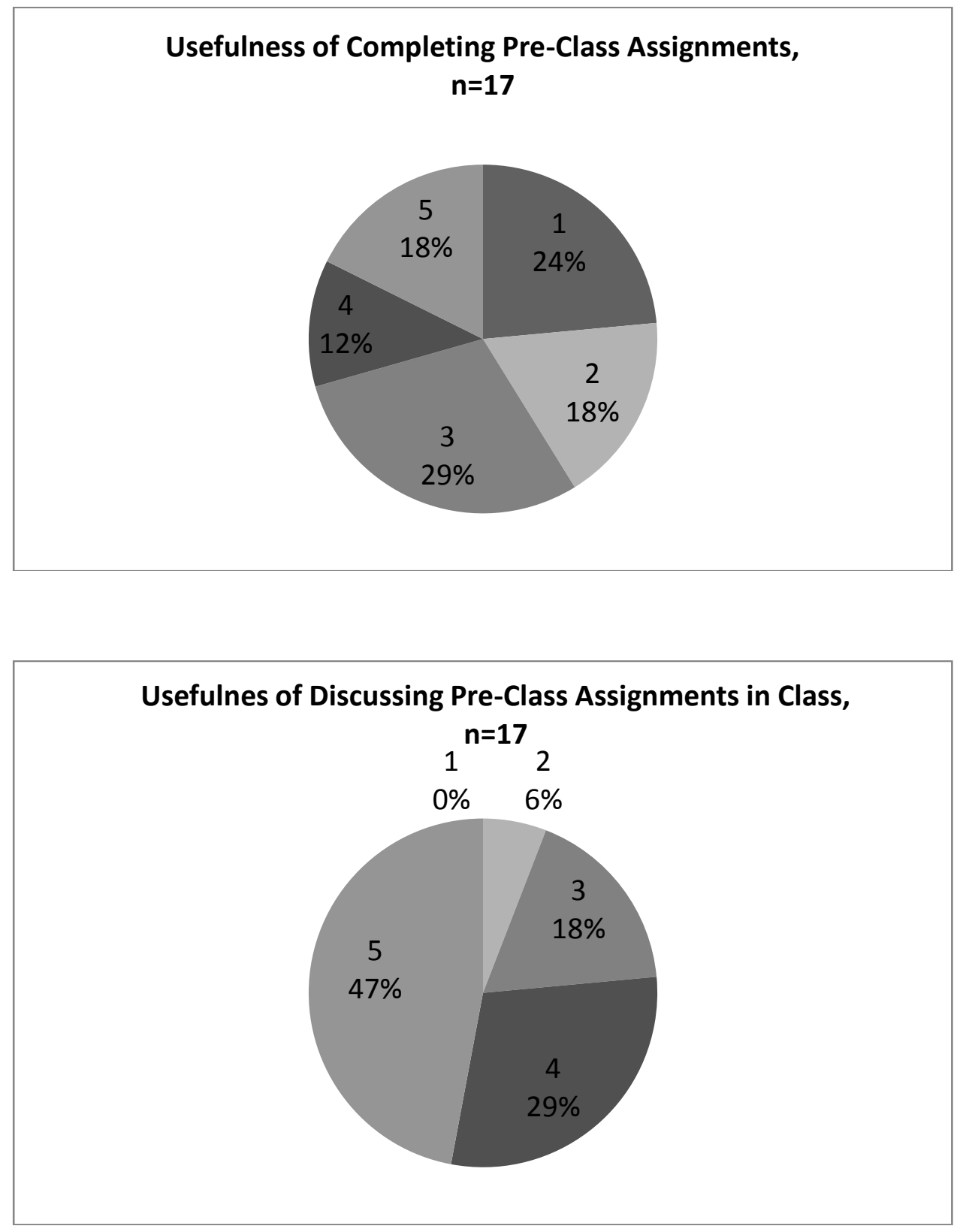
NOTES 